\title{
O cotidiano na terapia ocupacional: cultura, subjetividade e contexto histórico-social*
}

\section{The concept of daily life in occupational therapy: culture, subjectivity and the social and historical context}

\author{
Sandra Maria Galheigo ${ }^{(1)}$
}

\begin{abstract}
GALHEIGO, S. M. O cotidiano na terapia ocupacional: cultura, subjetividade e contexto históricosocial. Rev. Ter. Ocup. Univ. São Paulo, v. 14, n. 3, p. 104-9, set./dez. 2003.

RESUMO: Este artigo discute a utilização do conceito de cotidiano na Terapia Ocupacional. Faz uma revisão bibliográfica do uso do conceito pelas Ciências Sociais, Psicologia Social e Filosofia. A partir desta revisão, argumenta que o aspecto inovador do uso do conceito na Terapia Ocupacional está associado à mudança na proposição teórico-metodológica que, segundo a perspectiva crítica, busca a retomada da relação Sujeito-História. Contrapõe asssim o modelo positivista, que visa o treinamento das atividades da vida diária, à perspectiva histórico-social, que busca a ressignificação crítica do cotidiano do sujeito.
\end{abstract}

DESCRITORES: Atividades cotidianas. Terapia ocupacional/tendências. Literatura de revisão.

\section{INTRODUÇÃO}

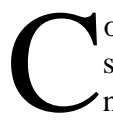

otidiano é um conceito que começa a ser utilizado em Terapia Ocupacional

álima década, quando algumas dissertações (ALMEIDA, 1993; TAKATORI, 1999) e publicações (ALMEIDA, 1997; CASTRO et al., 2001; FRANCISCO, 2001; TAKATORI, 2001) passam a incorporá-lo como unidade de análise. Entretanto, a idéia de vida diária impressa em seu significado vem sendo utilizada pela Terapia Ocupacional desde as suas origens. O que teria então de inovador na adoção deste conceito? Seu aparecimento é exclusivo ao domínio da Terapia Ocupacional ou tem ele ressurgido enquanto

\footnotetext{
* Trabalho apresentado no painel Cotidiano, Cultura e Subjetividade no VIII Congresso Brasileiro de Terapia Ocupacional e V Congresso Latino-Americano de Terapia Ocupacional, realizado em Foz do Iguaçu, Paraná, de 2 a 6 de junho de 2003.

(1) Professora Titular da Faculdade de Terapia Ocupacional da Pontifícia Universidade Católica de Campinas, PUC-Campinas. Doutora em Ciências Sociais pela Universidade de Sussex, Reino Unido.

Endereço para correspondência: Profa. Sandra Maria Galheigo, Faculdade de Terapia Ocupacional, Centro de Ciências da Vida, PUC-Campinas. Av. John Boyd Dunlop, s/nº, Jardim Ipaussurama, 13.059-740. Campinas, SP, e-mail: sandramg@terra.com.br
} 
um organizador de determinadas idéias em diferentes disciplinas nas últimas décadas? Este artigo se propõe a apresentar seu surgimento em disciplinas afins e refletir sobre as mudanças em sua utilização. Indo além, busca aprofundar os princípios que fizeram os objetivos da Terapia Ocupacional caminharem do treinamento das atividades da vida diária para a ressignificação do cotidiano. Para tal, irá contrapor individualidade e singularidade, buscando no contexto histórico-social, na cultura e nos processos de subjetivação do mundo contemporâneo a fundamentação para o uso do conceito de cotidiano na Terapia Ocupacional.

\section{Quando o cotidiano entra em cena...}

Uma consulta rápida a livros de pedagogia, serviço social, psicologia social e sociologia que contém em seus títulos a palavra cotidiano e suas derivações é suficiente para mostrar a freqüência como que, na última década, o dia-a-dia das escolas, das cidades e dos atores sociais em seus diferentes percursos passou a ser foco da atenção de pesquisadores, estudiosos e profissionais assistenciais. Evita-se falar sobre um fenômeno, de fora, de uma perspectiva teórica, com a devida distância sujeito-objeto, para, ao contrário, buscar-se conhecer através do olhar de alguém, de dentro, compartilhando vivências, desvendando representações, sentidos e significados. Portanto, acredita-se que é o estudo das práticas sociais, que atravessam o cotidiano, que possibilita a compreensão da realidade social e abre as portas para sua transformação.

Este tem sido o enfoque metodológico utilizado para se estudar inúmeros fenômenos, eventos e práticas. O foco está na compreensão que o próprio sujeito tem de aspectos de sua vida cotidiana, seja a compreensão da violência pelos jovens (MINAYO et al., 1999), o entendimento que motoristas de ônibus têm da penosidade de seu trabalho (SATO, 1995), a discussão sobre as conversas do cotidiano acerca da menopausa (MENEGON, 2000), a representação que pessoas com LER/DORT têm de sua dor (MAGALHÃES, 1998) ou a compreensão de idosos sobre sua participação em programas de lazer em grupos de terceira idade (BORINI, 2002), dentre inúmeros outros exemplos. O estudo dos fenômenos sociais, sejam as conversas, os mitos, as religiões, as ideologias, possibilita o acesso à compreensão das representações sociais no cotidiano a partir do senso comum e dos saberes populares. Pretendese assim romper com o dualismo individual - coletivo, sem entretanto, reduzir um ao outro. Afinal,

todas as culturas que conhecemos possuem instituições e normas formais que conduzem, de uma parte, à individualização, e de outra, à socialização. As representações que elas elaboram carregam a marca desta tensão, conferindo-lhe um sentido e procurando mantê-las nos limites do suportável. Não existe sujeito sem sistema nem sistema sem sujeito. O papel das representações partilhadas é o de assegurar que sua co-existência é possível (MOSCOVICI, 1998, p. 12).

$\mathrm{O}$ enfoque na pesquisa social de caráter qualitativo ganhou destaque a partir dos anos 50, principalmente com trabalhos de Goffman (1974) sobre as instituições totais, abrindo assim espaço crescente para o estudo de pequenos grupos como processo para a compreensão da realidade social cotidiana. No Brasil, tais abordagens passam a ganhar espaço principalmente a partir dos anos 80 (FERREIRA, 1979). Tais métodos de pesquisa e teorização examinam como o mundo social é criado ao se compartilhar significados através de um processo inter-subjetivo. O Senso Comum passa a adquirir destaque na pesquisa ao acreditar-se que se tem acesso à realidade social objetiva através da interpretação que as pessoas dela fazem. A Fenomenologia de Schutz (MAY, 1993; MINAYO, 1998, 1999), assim como a Etnometodologia de Garfinkel (MAY, 1993; MINAYO, 1999), se configura, portanto, nas Ciências Sociais como a Sociologia da Vida Cotidiana (MINAYO, 1999). Ambas surgem para preencher a lacuna deixada pelas correntes positivistas e marxistas na compreensão da subjetividade do ser social que se manifesta na leitura do significado que os atores sociais atribuem à vida cotidiana. A Etnometodologia e a Fenomenologia vêm assim se contrapor às correntes positivistas, assentadas no estudo da realidade a partir do fato que só pode ser apreendido pelos sentidos, e às correntes marxistas, mais interessadas nas abordagens filosóficas ou macro-sociais (MINAYO, 1999).

Entretanto, há que se pensar se a realidade pode ser reduzida à concepção que os homens fazem dela. $\mathrm{O}$ debate, se há um espaço entre a a teoria social e a interpretação que os homens fazem da vida social, subjaz um debate maior entre teoria sociológica e pesquisa social, entre a macro-teoria, que preocupa-se com o comportamento do conjunto das pessoas e as análises das estruturas e sistemas sociais, e a micro-teoria que preocupa-se com a interação face a face entre pessoas no seu cotidiano (MAY, 1993). Se ambas se preocupam com problemas com os quais nos deparamos na realidade social, adotam, por outro lado, abordagens distintas de tais questões. Os teóricos tendem a pensar a cena social, dissociando-a das ações cotidianas. Permitem assim que se localize os resultados da pesquisa social dentro de uma teoria geral maior que serve de arcabouço para a compreensão da dinâmica social. Entretanto, seu grau 
de generalização pode ser insuficiente para a compreensão de um território específico da vida social, locus da micro-teoria (MAY, 1993).

A teoria crítica em particular enfatiza as relações de dominação existentes na sociedade e que permeiam a questão do significado cotidiano. Parte do princípio de que não existe uma verdade que possa ser alcançada pela utilização de técnicas de pesquisa social. Para os teóricos críticos compreender tais relações de dominação traz em si a possibilidade de sua mudança. Por isso, criticam Schultz e Garfinkel como sendo conservadores, na medida em que julgam que estes não buscam o desafio da transformação social (MAY, 1993). Foucault (1978, 1983, 1984), igualmente busca documentar que as relações do saber e do poder, manifestadas nas formas de controle social do cotidiano pela disciplinarização e normatização, só podem ser conhecidas como tal numa análise que vá além do simples conhecimento das práticas cotidianas e das concepções que as pessoas delas fazem.

\section{Cotidiano como foco da reflexão filosófica}

A vida cotidiana se constituiu como objeto de reflexão filosófica através dos trabalhos de Henri Lefèbvre, Georg Lukács e Agnes Heller. Para Lefèbvre, o cotidiano é mais do que um conceito, na medida em que a crítica à vida cotidiana permite apreender as criações humanas, as idéias, os valores e sentimentos, possibilitando conhecer a própria sociedade. No cotidiano tanto a repetição como a inovação ganham forma. A vida cotidiana, portanto, pode ser entendida:

como o centro real da práxis, onde se realiza o movimento de produção e de reprodução das relações sociais, onde se dá a produção do ser humano, no curso de seu desenvolvimento histórico (LIMA, 1983, p.43, grifo do autor).

Entretanto, Lefèbvre salienta que há que se pensar a alienação implícita na vida cotidiana cujo equacionamento apenas se dá a partir de um distanciamento crítico do cotidiano, quando então novas relações sociais podem ser pensadas (LIMA, 1983).

"A programação do cotidiano tem meios poderosos: ela tem seus acasos e também a iniciativa, $o$ impulso da 'base' que faz balançar todo o edifício" (LEFÈBVRE, 1981 apud CARVALHO, 2000, p. 50).

Portanto, para Carvalho (2000), os estudos de Lefèbvre revelam três perspectivas na apreensão do cotidiano: a busca do real e da realidade (em seus aspectos práticos e abstratos), a compreensão do cotidiano a partir da totalidade e a possibilidade da transformação social.

Os componentes essenciais da vida cotidiana segundo a perspectiva marxista foram desenvolvidos, ao longo das últimas quatro décadas também nos trabalhos de Georg Lukács e de sua discípula Agnes Heller(NETTO, 2000).

Segundo estes autores, todas as sociedades a seu tempo e contexto produzem sua própria cotidianidade. Mudam a organização do espaço e do tempo, os comportamentos individuais e coletivos, as formas de produção e atividades principais, mas a estrutura da vida cotidiana lá continua, insuprimível. O cotidiano, portanto, "não está fora da história, mas no centro do acontecer histórico" (HELLER, 2000, p. 20).

A cotidianidade é desenvolvida do nascimento à maturidade, quando gradativamente assimila-se a manipulação das coisas, a realização das tarefas diárias e a dinâmicas das relações sociais. Ao longo da vida e da história, atividades variadas assumem papel preponderante, para serem mais tarde descartadas ou modificadas conforme chegue o limite do tempo individual, uma conquista coletiva ou uma mudança sócio-histórica. A cotidianidade varia conforme o contexto, isto é, varia conforme a classe social, os laços culturais, o gênero, a idade. Segue os ritmos e as regularidades de cada tempo histórico (CARVALHO, 2000).

A vida cotidiana é heterogênea em conteúdo e significação. Inúmeras atividades humanas compõem o dia-a-dia. Segundo Heller (2000, p. 18), “(S)ão partes orgânicas da vida cotidiana: a organização do trabalho e da vida privada, os lazeres e o descanso, a atividade social sistematizada, o intercâmbio e a purificação".

O cotidiano traz em si a marca da singularidade do sujeito, e toma forma a partir de suas necessidades, valores, crenças e afetos. Nesse sentido, o cotidiano de cada pessoa é único e irrepetível na medida em que a unicidade e a irrepetibilidade são características inequívocas da condição humana. Entretanto, segundo Heller (2000, p.21), “o genérico está ‘contido' em todos os homens e, mais precisamente, em toda a atividade que tenha caráter genérico, embora seus motivos sejam particulares". Assim, o sujeito individual se transforma no sujeito coletivo, seja através da atividade artística, laborativa ou científica, nas atividades de cuidado do outro (das crianças, dos doentes e necessitados), ou nas atividades relativas à participação social e política.

Contudo, se o cotidiano do homem é produzido por esse ser singular e genérico, aí não se esgotam as formas de sua produção. O Estado, as instituições e corporações são produtores e controladores tenazes da vida cotidiana. Nas sociedades capitalistas contemporâneas, a manutenção da constante produção dos bens de consumo faz com que se trabalhe na constante produção do desejo. Fica cada vez mais difícil 
discernir necessidades reais das construídas. Isto se deve ao processo de comodificação do cotidiano expresso na produção de utensílios para a manutenção de uma vida confortável e saudável, na construção corporativa da atividade lúdica infantil (STEINBERG; KINCHLOE, 2001) e na fetichização da vida privada e cotidiana apresentada nos reality shows.

O cotidiano, alimentado pelos bens de consumo, profissionalizado e mecanizado em suas tarefas rotineiras, tem levado ao afastamento das interações pessoais facea-face e ao constante esvaziamento do processo do fazer humano, que perde gradualmente reconhecimento social. A comunicação via Internet e a hiper-realidade vem igualmente transformando as relações sociais e com o mundo concreto.

Ao mesmo tempo, os processos de disciplinarização, normatização e normalização do cotidiano de pessoas submetidas à regulação do Estado, das instituições e das organizações continuam a se desenvolver em seus mínimos detalhes. Na verdade, a informatização dos mecanismos de controle social tem levado o legado da vigilância ao âmago da vida cotidiana.

\section{Do treinamento das atividades da vida diária à ressignificação do cotidiano: subjetividade, cultura e contexto sócio-histórico}

A concepção de cotidiano, seja na vertente sociológica ou filosófica, vem se contrapor às perspectivas positivistas que acreditam ser fundamental se distinguir fatos de valores, adotando-se assim uma postura de neutralidade que possibilite uma análise mais objetiva da realidade social. O positivismo sociológico parte do pressuposto de que a sociedade humana funciona harmônica e consensualmente segundo as leis da natureza. $\mathrm{Na}$ mesma linha de pensamento, fatos devem ser estudados e decompostos em seus elementos mais simples, buscando-se assim desvendar leis invariáveis e independentes do funcionamento social.

Na medida em que os estudos sobre o cotidiano incorporam a subjetividade, a cultura, a história e o poder social como elementos que influem na compreensão do fenômeno, eles definitivamente rompem com qualquer leitura de caráter mais positivista. Afirmam, desta forma, que valores mudam de acordo com as diferentes culturas, mudam ao longo da história e podem ser diferentes mesmo dentro de uma mesma sociedade em determinado momento. Portanto, o que pode ser problema para um grupo social não o é para o outro. Pesquisadores e profissionais devem assim colocar em perspectiva as variações encontradas acerca de determinado fenômeno.

É aí que vem se colocar a entrada do conceito de cotidiano nos estudos de terapia ocupacional. Ele surge, portanto, não como mais um modismo mas como uma busca, intencional ou não, de se fazer uso de conceitos que mais se afinem às leituras e proposições críticas da ação da terapia ocupacional.

Percebe-se assim que a noção de cotidiano surge com a pretensão de substituir os conceitos de atividades da vida diária e atividades da vida prática. Se retomarmos a origem destes dois conceitos na terapia ocupacional assim como a formatação de seu uso em formulários de avaliação, identifica-se de imediato a perspectiva positivista de obtenção de fatos e de sua mensuração com o objetivo de avaliação e planejamento da intervenção terapêutica. Em geral as avaliações são compostas de longas listas de atividades de auto-cuidado, automanutenção, tarefas domésticas e comunicação, dentre outras, que, ao serem analisadas em seus detalhes, se desdobram em tarefas, e até em etapas, mais específicas. Em sua elaboração parte-se usualmente do princípio de que esses fazeres rotineiros são universais e devem ser elencados em categorias únicas. Da avaliação e detecção de dificuldades em alguns ou vários de seus repertórios é que se formula o treinamento, que tem a intenção de favorecer a independência do indivíduo, como querem alguns, ou sua autonomia, como preferem outros. Como afirma Francisco (2001):

\begin{abstract}
...as atividades da vida diária vêm sendo compreendidas e utilizadas, em larga escala, pelos terapeutas ocupacionais como repetição mecânica de atos/ações físicas exigidos para que se efetive o dia-a-dia, cujo sentido não é questionável (p. 75).
\end{abstract}

A partir do exposto é razoável afirmar que os conceitos de atividades da vida diária (AVDs) e atividades da vida prática (AVPs) são a-históricos, sendo utilizados de forma indiscriminada e descontextualizada nos livros e nas práticas de terapia ocupacional ao longo das décadas. Igualmente, em maior ou menor graus, pode-se afirmar que não incorporam a diversidade cultural e social na sua concepção.

As AVDs eAVPs vêm a compor o que Francisco (2001) veio a chamar de modelo do exercício. Neste, "terapeutas ocupacionais tornam-se especialistas em exercícios progressivos de resistência, em atividades da vida diária, em suportes funcionais, no desenvolvimento pré-vocacional, etc.” (FRANCISCO, 2001, p. 31). Segundo este modelo, o processo de coleta de dados da avaliação inicial consiste em fazer uso das anamneses e das entrevistas estruturadas ou semi-estruturadas onde informações a respeito do desempenho nas AVDs e AVPs são colhidas, as respostas são posteriormente sistematizadas, analisadas e os problemas identificados 
são convertidos em objetivos de tratamento.

A incorporação do conceito de cotidiano na produção teórica e no discurso da prática traz implícita uma mudança radical na proposição teóricometodológica da terapia ocupacional. A ação da terapia ocupacional, segundo a perspectiva crítica, funda-se na retomada histórica e contextualizada do sujeito e sua inserção participante no coletivo.

A afirmação acima nos remete, inicialmente, a pensar o papel da subjetividade na vida cotidiana. Afinal, como sinaliza Heller (2000, p. 17), "a vida cotidiana é a vida do homem inteiro", onde colocam-se "seus sentidos, todas as suas capacidades intelectuais, suas habilidades manipulativas, seus sentimentos, paixões, idéias, ideologias”.

Quando focamos na subjetividade, nos atemos aos significados que as pessoas dão às suas experiências, isto é, a compreensão e interpretação que fazem de sua realidade social. Tal visão traz em si a idéia de que elas têm (ou buscam ter) autonomia de determinar o curso de suas vidas, exercendo livremente seus pensamentos e indo de encontro a seus desejos e anseios. Tal afirmação, entretanto, torna-se problemática se for reduzida a uma visão individualista, auto-centrada, forjada pelo liberalismo e pela sociedade de consumo. Ao contrário, o processo de singularização implica em se recusar a submeter-se a um papel social tal como o recebe numa relação de alienação e opressão, e reapropriar-se de forma criativa dos componentes da subjetividade, produzindo assim o que Guatarri e Rolnik (2000) vêm a chamar de subjetividade singular.

Heller (2000) argumenta que a inserção no cotidiano se manifesta numa dupla condição: através da "consciência do Eu" e da "consciência de nós"; assim, a condição humana se revela simultaneamente no ser particular e no ser genérico. O humano-genérico é exatamente aquele que se orienta para o "nós", para o coletivo e se manifesta na arte, no trabalho, na ética. A cotidianidade, portanto, se dá no encontro do singular e do coletivo ao buscar a satisfação das necessidades pessoais e, também, das necessidades coletivas.

Assim, lidar com o cotidiano é sempre intervenção que exige um lidar com a concretude do homem, esse movimento de múltiplas relações. O cotidiano não é rotina, não é a simples repetição mecânica de ações que levam a um fazer por fazer. O cotidiano é o lugar onde buscamos exercer nossa prática transformadora, é o social; é o contexto em que vivemos (FRANCISCO, 2001, p. 76).

A vida cotidiana do sujeito se revela no entroncamento da realidade exterior e da realidade psíquica, na rede de suas relações sociais, nas atividades costumeiras de auto-cuidado e auto-manutenção, nas manifestações de solidariedade. O terapeuta ocupacional tem, portanto, uma posição privilegiada ao poder contribuir para a elaboração crítica do cotidiano do sujeito. O poder refletir a vida cotidiana e suas determinações, esse olhar estrangeiro para o que parece rotina imutável, contribui de forma marcante para os movimentos de auto-determinação do sujeito, de reorganização do coletivo e ressignificação do cotidiano.

O conhecer a vida cotidiana implica na utilização de metodologias diferentes das empregadas na avaliação das AVDs. Se apreender o cotidiano implica em entender como se dá a relação sujeito-cotidianohistória-sociedade, as metodologias mais adequadas são as de caráter qualitativo, que possibilitam a compreensão subjetiva da realidade social e permitem ao sujeito se perceber como resultado de múltiplas determinações. Trabalhar com histórias e mapas ocupacionais, histórias de vida, narrativas e biografias permite ao sujeito recontar sua própria história, re-significar seu cotidiano e se reconhecer como "fazedor de sua história e da história do mundo" (FRANCISCO, 2001, p. 67).

GALHEIGO, S. M. The concept of daily life in occupational therapy: culture, subjectivity and the social and historical context. Rev. Ter. Ocup. Univ. São Paulo, v. 14, n. 3, p. 104-9, set./dez. 2003.

ABSTRACT: This article discusses the use of the concept of daily life in Occupational Therapy. It presents a bibliographic review of the use of the concept in Social Science, Social Psychology and Philosophy. After that it argues that the inovation in the use of the concept is associated with changes in theoretical and methodological assumptions since the critical perspective seeks to address the relationship between Subject and History. It opposes the positivist model, which aims at the training of activities of daily living, to the critical perspective, which seeks to attribute critical meaning to the daily life of the subject.

KEY WORDS: Activities of daily living. Occupational therapy/trends. Review literature. 


\section{REFERÊNCIAS}

ALMEIDA, M. A pessoa portadora de deficiência física em seu cotidiano: reflexo e reflexões sobre a reabilitação. 1993. 117f. Dissertação (mestrado) - Instituto de Psicologia, Universidade de São Paulo. São Paulo, 1993.

ALMEIDA, M. Deficiência e cotidiano: reflexões sobre a reabilitação. Rev. Ter. Ocup. Univ. São Paulo, v. 8, p. 81-6, 1997.

BORINI, M.L. A saída do fundo do poço: representações sociais acerca da participação em atividades de lazer em grupos de terceira idade. 2002. 98f. Dissertação (mestrado) - Faculdade de Ciências Médicas, Universidade Estadual de Campinas. Campinas, 2002.

CARVALHO, M. C. O conhecimento da vida cotidiana: base necessária à prática social. In: CARVALHO, M. C.; NETTO, J. P. Cotidiano: consciência e crítica. São Paulo: Cortez, 2000. p.17-63.

CASTRO, E.; LIMA, E.; BRUNELLO, M. I. Atividades humanas e terapia ocupacional. In: CARLO, M.; BARTALOTTI, C. (Org.). Terapia ocupacional no Brasil: fundamentos e perspectivas. São Paulo: Plexus Editora, 2001.

FERREIRA, R. Meninos da rua: valores e expectativas de menores marginalizados em São Paulo. São Paulo: CEDEC, 1979. $173 p$.

FOUCAUlt, M. História da loucura. São Paulo: Perspectiva, 1978. 551p.

FOUCAULT, M. Vigiar e punir. Petrópolis: Vozes, 1983. $277 \mathrm{p}$.

FOUCAULT, M. Microfísica do poder. 4.ed. Rio de Janeiro: Graal, 1984. 295p.

FRANCISCO, B. Terapia ocupacional. 2.ed. Campinas: Papirus, 2001.

GOFFMAN, E. Manicômios, prisões e conventos. São Paulo: Perspectiva, 1974. 312p.

GUATARRI, F.; ROLNIK, S. Micropolítica: cartografias do desejo. 6.ed. Petropólis: Vozes, 2000.

HELLER, A. O cotidiano e a história. 6.ed. São Paulo: Paz e Terra, 2000. 121p.

LIMA, S. Participação social no cotidiano. 5.ed. São Paulo: Cortez, 1983. 157p.

MAGALHÃES, L. A dor da gente: representações sociais sobre as lesões por esforços repetitivos. 1998. 224f. Tese (doutorado). Faculdade de Ciências Médicas, Universidade Estadual de Campinas. Campinas, 1998.

MAY, T. Social research: issues, methods and process. Buckingham: Open University Press, 1993. 193p.

MENEGON, V. M. Por que jogar conversa fora? Pesquisando no cotidiano. In: SPINK, M. J. Práticas discursivas e produção de sentidos no cotidiano: aproximações teóricas e metodológicas. São Paulo: Cortez, 2000. p. 215-41.

MINAYO, M. C. S., et al. Fala galera: juventude, violência e cidadania na cidade do Rio de Janeiro. Rio de Janeiro: Garamond, 1999. 240p.

MINAYO, M. C. S. O conceito de representações sociais dentro da sociologia clássica. In: GUARESCHI, P.; JOVCHELOVITCH, S. Textos em representações sociais. 4.ed. Petropólis: Vozes, 1998. p.89-111.

MINAYO, M. C. O desafio do conhecimento: pesquisa qualitativa em saúde. 6.ed. São Paulo: Hucitec; Rio de Janeiro: ABRASCO, 1999. 269p.

MOSCOVICI, S. Prefácio. In: GUARESCHI, P.; JOVCHELOVITCH, S. Textos em representações sociais. 4.ed. Petropólis: Vozes, 1998. p.7-16.

NETTO, J. P. Para a crítica da vida cotidiana. In: CARVALHO, M. C.; NETTO, J. P. Cotidiano: consciência e crítica. São Paulo: Cortez, 2000. p.64-93.

SATO, L. A Representação social do trabalho penoso. In: SPINK, M. O conhecimento no cotidiano: as representações sociais na perspectiva da psicologia social. São Paulo: Brasiliense, 1995. p. 188-211.

STEINBERG, S.; KINCHLOE, J. Sem segredos: cultura infantil, saturação de informação e infância pós-moderna. In: STEINBERG, S.; KINCHLOE, J. Cultura infantil: a construção corporativa da infância. Rio de Janeiro: Civilização Brasileira, 2001. p.11-52.

TAKATORI, M. O brincar no cotidiano da criança com deficência física: privilegiando um olhar para a construção das intervenções em reabilitação. 1999. 233f. Dissertação (mestrado) - Instituto de Psicologia da Universidade de São Paulo, São Paulo, 1999.

TAKATORI, M. A terapia ocupacional no processo de reabilitação: construção do cotidiano. Mundo da Saúde, v. 25 , p. 371-7, 2001. 